\title{
Potential use of cerebrospinal fluid serotonin level as a marker of neuronal injury after exposure to 3, 4-Methylenedioxymethamphetamine
}

Dear Editor,

The trend of drug use has changed tremendously in this millennium (Adnan et al., 2014). Over the past decade, opioids are among the primary drug of abuse in worldwide. However the trend towards using amphetamine-type stimulant (ATS) is notably increasing lately. Amphetamine-type stimulants are a group of drugs consisting mainly of amphetamine and metamphetamine; these include methcathinone, fenetylline, ephedrine, pseudoephedrine, methylphenidate and 3, 4Methylenedioxymethamphetamine (MDMA) or 'ecstasy' (WHO, 2014).

Parallel to the increasing trend of MDMA abuse, an increasing number of researches are also on their way. Some of the researches focus on exploring the effect of this substance on the tissue especially on the brain. The main effect of MDMA is to cause the release of serotonin neurotransmitter from the axon terminal in the brain and also interfere with the storage of serotonin within its vesicles with subsequent increase in the amount of serotonin being released into the synapse (Ma et al., 2013). Therefore, brain tissue is the main sample used in majority of the previous animal studies. Most of those animal studies evaluated the biochemical with behavioral changes, but very occasional studies were done to evaluate the histological changes in the brain and correlated with the biochemical changes. Murnane et al. (2012) in his studies has demonstrated the histopathological changes caused by the exposure to amphetamine. This would be more interesting in the findings were also correlated with the biochemical changes in the brain.

However, brain samples are not suitable to be used for comparison of biochemical analysis with the changes in the brain histopathology. Considering that, another alternative is to use the cerebrospinal fluid (CSF). This fluid is secreted by epithelial cells lining the choroid plexuses of the brain ventricles and is in communication with the brain extracellular space, thus allowing it to provide information about the biochemical and pharmacokinetics activity of the brain tissue. It can also be used to assess the pharmacokinetics of peripherally administered brainpenetrant compounds (Lin, 2008). Levels of the serotonin and its main metabolite 5-hydroxyindoleacetic acid (5-HIAA) in the CSF were found to reflect the concentration released during the neuronal activity in the brains (Harold, 2001). Furthermore, the serotonin level released in cerebrospinal fluid rat also provides better index for functionally active of serotonergic system (Anderson et al., 1987; Matsumoto et al., 1991). The used of CSF in the evaluation of biochemical changes in central nervous system following brain injury, stroke, and post-surgical recovery has been suggested by Maurer (2010).

As a conclusion, CSF is a potential sample to be used in the evaluation of the neuronal damage following exposure to MDMA. However, further evaluation on serotonin levels and correlation with histological changes representing neuronal damage need to be conducted in order to provide more understanding on its use.

\section{Fatin Haniza Zakaria ${ }^{\text {a,c* }}$, Nor Hidayah Abu

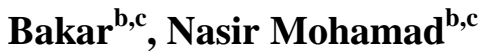

${ }^{a}$ MSc candidate Faculty of Medicine, Universiti Sultan Zainal Abidin (UniSZA), 20400, Kuala Terengganu, Terengganu, Malaysia.

${ }^{\mathrm{b}}$ Medical lecturer, Faculty of Medicine, Universiti Sultan Zainal Abidin (UniSZA), 20400, Kuala Terengganu, Terengganu, Malaysia

'Opioid Research Interest Group, Faculty of Medicine, Universiti Sultan Zainal Abidin (UniSZA), 20400, Kuala Terengganu, Terengganu, Malaysia.

*For correspondence: Email: fatinhaniza1992 @ gmail.com

\section{REFERENCES}

Anderson GM, Teff KL, Young SN. Serotonin in cisternal cerebrospinal fluid of the rat: measurement and use as an index of functionally active serotonin. Life Sci, 1987:40: 2253- 60.

Harold, Kalant. The pharmacology and toxicology of "ecstasy" (MDMA) and related drugs. CMAJ., 2001: Oct 2; 165(7): 917-928.

Kevin Sean Murnane, Shane Alan Perrine, Brendan James Finton, Matthew Peter Galloway, Leonard Lee Howell, William Edward Fantergrossi. Effects of exposure to amphetamine derivates on passive avoidance performance and the central levels of monoamines and their metabolites in mice: Correlations between behaviour and neurochemistry. Psychopharmacology, 2012: $220: 495-508$. 
Lin, Jiunn H. CSF as a Surrogate for Assessing CNS Exposure: An Industrial Perspective. Current Drug Metabolism, 2008: 46-59.

Liyana hazwani Mohd Adnan, Nor Hidayah Abu Bakar, Nasir Mohamad. Post Millennium Preference of Substance Abuse among Teenagers: Fast and Furious. Journal of Applied Pharmaceutical Science, 2014: 131-132.

Matsumoto M, Togashi H, Yoshioka M, Morii K, Hirokami M, Tochihara M, Ikeda T, Saito Y, Saito H. Significant correlation between cerebrospinal fluid and brain levels of norepinephrine, serotonin, and acetylcholine in anesthetized rats. Life Sci , 1991: 48:823- 829.

Maurer, Martin H. Proteomics of brain extracellular fluid (ECF) and cerebrospinal fluid (CSF). Mass Spectrometry Reviews, 2010: 17-28.
Organization, World Health. World health statistics 2014. World Health Organization, 2014.

Zhiyuan Ma, Mary Rudacille, Howard M. Prentice and Rui Tao. Characterization of electroencephalographic and biochemical responses at 5-HT promoting drug-induced onset of serotonin syndrome in rats. Journal of Neurochemistry, 2013: 774789 .

\section{How to cite this article:}

Zakaria FH, AbuBakar NH, Mohamad N. Potential use of cerebrospinal fluid serotonin level as a marker of neuronal injury after exposure to 3, 4-Methylenedioxymethamphetamine. J App Pharm Sci, 2017; 7 (09): 252-253. 